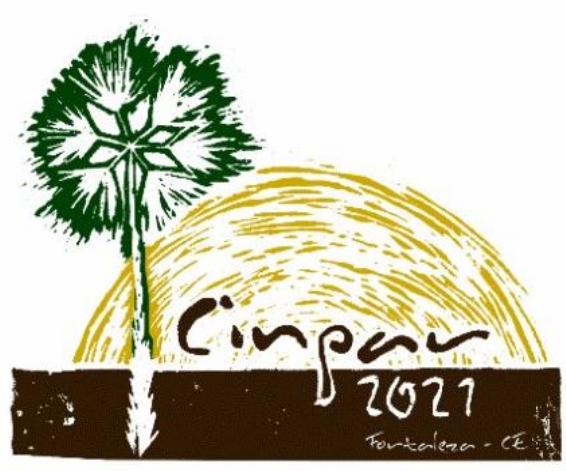

XVII Congresso Internacional sobre Patologia e

Reabilitação das Construções

XVII Congreso Internacional sobre Patología y Rehabilitación de las Construcciones

XVII International Conference on Pathology and Constructions Rehabilitation

FORTALEZA (Brasil), 3 a 5 de junho de 2021

https://doi.org/10.4322/CINPAR.2021.011

\title{
PRINCIPAIS MANIFESTAÇÕES PATOLÓGICAS DE UM EDIFÍCIO EM ANÁPOLIS-GO
}

\section{MAIN PATHOLOGICAL MANIFESTATIONS OF A BUILDING IN ANÁPOLIS-GO}

\author{
Guilherme TEIXEIRA ${ }^{1}$, Juliano SILVA ${ }^{2}$, Eder ALVES ${ }^{3}$ \\ ${ }^{1}$ Universidade Estadual de Goiás, Anápolis-GO, Brasil, guilherme.henrique.eng@hotmail.com \\ ${ }^{2}$ Universidade Estadual de Goiás, Anápolis-GO, Brasil, julianorodriguessilva@gmail.com \\ ${ }^{2}$ AGETOP, Anápolis-GO, Brasil, eder.chaveiro@gmail.com
}

\begin{abstract}
Resumo: Esse trabalho visa apresentar as principais manifestações patológicas de um edifício em AnápolisGO. As manifestações patológicas foram identificadas através da inspeção predial, in loco, por meio da vistoria visual e de acordo com as diretrizes da Norma de Inspeção Predial do Instituto Brasileiro de Avaliações e Perícias de Engenharia - IBAPE (2012), no seu Nível de inspeção 01, as especificações da ABNT NBR 5674 (1999) - Manutenção de edificações - Procedimento e da ABNT NBR 16747 (2020) - Inspeção predial - Diretrizes, conceitos, terminologia e procedimentos. Para o desenvolvimento do trabalho apenas as manifestações com grau de risco crítico e regular foram expressas. Além disso, foi determinado o grau de risco de cada manifestação, as possíveis causas, propostas de intervenções, períodos para aplicação das mesmas e a prioridade de intervenção. É necessário atenção nas manifestações patológicas identificadas nos pilotis e reservatório, as quais possuem grau crítico e necessitam de intervenção imediata, pois podem comprometer a estrutura da edificação. Dessa forma, nota-se que a maioria dos elementos vistoriados apresentaram, como causa geral das manifestações patológicas, a ausência de manutenção que associada com o seu respectivo agente causador provocaram o agravamento da situação para aquela em que a estrutura se encontra.
\end{abstract}

Palavra-chave: Patologia; edifícios; carbonatação; impermeabilização

Abstract: This paper has goals presentes the main pathological manifestations of a building in Anápolis-GO. The pathological manifestations were identified through of building inspection, in loco, through of visual inspection and according to guidelines building inspection standard of Brasilian Insitute of Engineering Assessment and Expertise - IBAPE (2012), in its Inspection level 01, the specifications of ABNT NBR 5674 (1999) - Building Maintenance Standard and the ABNT NBR 16747 (2020) - building inspection-Guidelines, concepts, terminology and procedure. For development this paper only the manifesstations with critical degree of risck was demonstrated. Besides that, it was determined the degree of risck of each manifestation, the possible causes, intervention proposal, application time and the intervention priority. Attention is needed in the pathological manifestations identified in the pilots and water tank, wich have a critical degree and need immediate intervention, because the can compromise the building structure. In this way, it is observed that most of the elements inspected presented, as a general cause of the pathological manifestations, the default maintenance that associated with its respective causative agent caused the worsening of the situation to that in which it finds itself.

Keywords: Pathology; building; carbonation; waterproofing 


\section{Introdução}

Conforme Bolina, Tutikian e Helene (2019), a patologia da construção trata-se de uma ciência que busca estudar defeitos nas edificações e em seus materiais, com intuito de conhecer suas origens e a maneira como se manifestam. Parte desses estudos são realizados através das inspeções prediais, que segundo a NBR 16747 (ABNT, 2020) são procedimentos sistemáticos com objetivo de avaliar as condições técnicas, de uso, operação, manutenção e funcionalidade da edificação. A inspeção predial apresenta predominantemente caráter sensorial, ou seja, é realizada através dos sentidos, principalmente da visão.

As edificações, naturalmente passam por um processo de envelhecimento, porém é necessário realizar, periodicamente, um processo de manutenção, com intuito de garantir que seu desempenho continue satisfatório. Segundo Souza e Ripper (2009), naturalmente a estrutura apresenta uma queda no desempenho com o passar do tempo, mas as intervenções técnicas permitem que ela siga o curso normal da sua vida útil, sendo papel da patologia das estruturas identificar esse desempenho insatisfatório e avaliar a necessidade de intervenção imediata, pois não necessariamente significa que a estrutura está condenada.

No Brasil, diversas construções estão passando por um processo de envelhecimento sem que seja realizada intervenções técnicas. De modo que, quando realizadas, identifica-se elementos com um elevado grau de deterioração, o que segundo a Lei de Sitter (1984) citada por Tutikian e Pacheco (2013) resultará em um maior custo e maior dificuldade para solução. Desse modo, o estudo da patologia torna-se fundamental para garantir o aumento do tempo de vida útil das edificações, o qual é definido pela NBR 15575-1 (ABNT,2013), como 50 anos para a estrutura.

Diversos trabalhos sobre o assunto vem sendo publicados, como os desenvolvidos por Galindo et al. (2017), Morais et al. (2020) e Rios et al. (2020), os quais mostram a necessidade do acompanhamento das edificações, tendo em vista que elas são naturalmente expostas a um processo de envelhecimento e somado a isso, algumas falhas podem antecipar a degradação da construção e o surgimento de manifestações patológicas.

Dessa forma, esse trabalho tem como objetivo avaliar as principais manifestações patológicas identificadas em um edifício situado na cidade de Anápolis-GO, através de relatório fotográfico, e com as informações coletadas, estabelecer soluções para que seja possível sua recuperação e garantir o conforto e segurança dos usuários. Além disso, por meio desse trabalho procura-se contribuir para o desenvolvimento do campo da patologia, servindo de exemplo para trabalhos futuros e mostrando a importância da manutenção preventiva.

\section{Metodologia}

Para a realização dessa pesquisa foi executada a inspeção predial com base na vistoria visual da edificação, in loco, que possuíram como resultado uma análise técnica, sendo pautadas de acordo com as diretrizes da Norma de Inspeção Predial do Instituto Brasileiro de Avaliações e Perícias de Engenharia - IBAPE (2012), no seu Nível de inspeção 01, as especificações da ABNT NBR 5674 (1999) - Manutenção de edificações Procedimento e da ABNT NBR 16747 (2020) - Inspeção predial - Diretrizes, conceitos, terminologia e procedimentos.

De acordo com a Norma de Inspeção Predial - IBAPE (2012), as inspeções são classificadas em três níveis conforme os aspectos técnicos, de manutenção e operação da edificação. Dessa forma, a inspeção executada nessa edificação foi classificada como "Inspeção de Nível 01", sendo realizado uma análise expedita dos fatos e sistemas construtivos vistoriados, com a identificação de anomalias e falhas que se mostraram de forma aparente.

As falhas, identificadas através de um relatório fotográfico, foram devidamente classificadas, quanto a origem do problema, indicado as possíveis causa e intervenção necessárias para a solução. Além disso, com base na referida Norma de Inspeção Predial do IBAPE (2012), as manifestações patológicas são classificadas de acordo com o impacto que provocam aos usuários, ao meio ambiente e ao patrimônio. A classificação é realizada em três graus de risco (mínimo, regular e crítico). 
Dessa forma, para a execução desse trabalho optou-se apenas pela identificação das manifestações patológicas com grau de risco regular e crítico, visto que as mesmas exigem uma maior atenção e prioridade de manutenção.

\section{Manifestações Patológicas}

3.1 Reservatórios superiores - oxidação, exposição das armaduras do concreto e oxidação das tampas

Manifestações: Nas bordas das aberturas dos reservatórios superiores, há pequenos sinais de desgaste do concreto e, em alguns pontos, exposição da armadura do concreto. É possível que partes internas do reservatório apresentem corrosão das armaduras. Foram observadas também a oxidação do aço da tampa localizada sobre a base da abertura dos reservatórios superiores. A oxidação é o resultado da reação entre o ferro e o oxigênio na presença de umidade, formando o óxido de ferro, também conhecido como ferrugem. Nas Figuras 1 e 2 percebe-se a corrosão do aço

Classificação do Problema: falha na manutenção e anomalia construtiva.

Possíveis causas: A oxidação precoce das armaduras é ocasionada pelo pequeno recobrimento de concreto, que protege as armaduras do reservatório, além dos ciclos de molhagem e secagem constantes. A norma brasileira de concreto armado NB-1 (1979), que vigorava na época da construção do edifício, especificava cobrimentos de armaduras menores que as preconizadas atualmente, o que favorece o ataque de agentes agressivos carregados pelo vapor de água até o interior do concreto armado, diretamente nas armaduras. Este processo pode estar acontecendo de forma imperceptível, debaixo do concreto, embora não seja possível determinar ao certo. A oxidação das tampas e do berço dos reservatórios ocorrem pela exposição às intempéries com os ciclos de secagem e molhagem a que estão expostas.

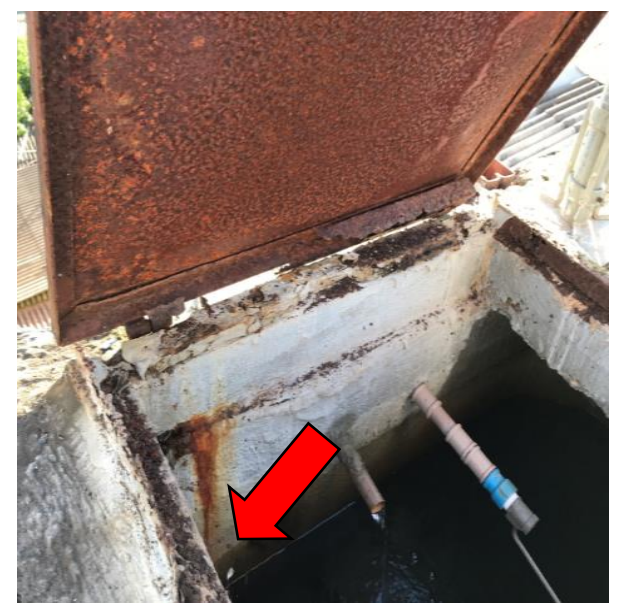

Figura 1 - Oxidação da armadura na borda interna dos reservatórios

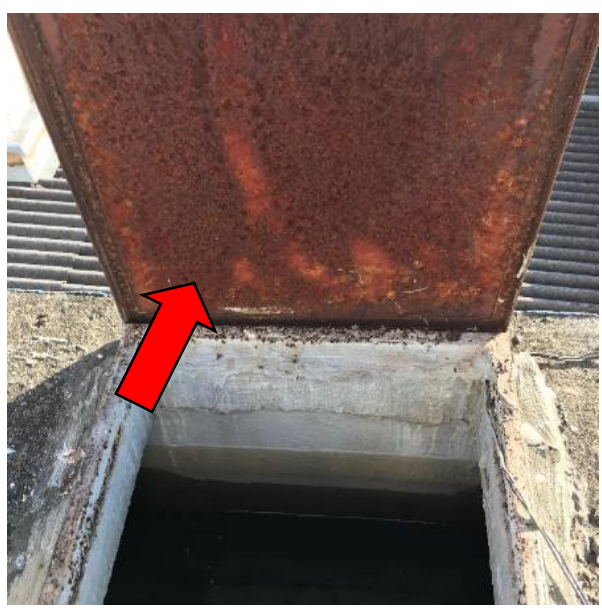

Figura 2 - Oxidação da tampa e do seu berço no reservatório superior

Intervenção: Recomenda-se remover a camada de concreto que recobre as armaduras das bordas internas ou no interior dos reservatórios que estejam eventualmente prejudicadas, e recompô-las, com espessura (cobrimento) maior, padronizada pela norma ABNT NBR 6118:2014, de 4,5 cm. Quanto as corrosões internas, estas sinalizam que devem ser recuperadas e reforçadas. Posteriormente realizar a impermeabilização da parte interna do reservatório, para impedir o fluxo de água através do concreto. As oxidações (ferrugens) encontradas nas tampas dos reservatórios não provocam prejuízo para a parte estrutural do edifício, porém é recomendado intervir. Nas bases das tampas das aberturas e nas próprias tampas que apresentarem corrosão, recomenda-se a remoção da ferrugem, aplicação de zarcão e pintura com tinta esmalte específica, ou a substituição do material, dando-se preferência, neste caso, para o alumínio, que não está sujeito ao problema de corrosão por não possuir o elemento ferro em sua composição. 
Risco: R (Grau regular)

\subsection{Reservatórios superiores - desgaste da impermeabilização interna do reservatório}

Manifestações: Foi observado que a impermeabilização do reservatório superior do prédio possui sinais de desgaste natural pelo tempo, como pode ser visto na Figura 3 e 4 .

Classificação do Problema: Falha na manutenção e anomalia construtiva;

Possíveis Causas: Desgaste natural da impermeabilização pelo tempo de uso.

Intervenção: Quanto ao desgaste natural pelo uso, sugere-se o monitoramento periódico do interior do reservatório para sinais de descascamento da impermeabilização e de sinais de infiltração nas paredes e piso do reservatório para proceder a troca do sistema de impermeabilização ou seu reforço.

Recomenda-se a remoção do material, até que seja atingida a superfície do concreto e a aplicação de impermeabilização com argamassa polimérica, observando o consumo de material mínimo indicado pelo fabricante. Recomenda-se o seguinte procedimento:

Com a superfície interna do reservatório isenta de poeira, óleo, graxa, nata de cimento, pinturas, partículas soltas, "nichos" de concretagem, pontas de ferro, restos de madeira, agentes de cura química ou desmoldantes e quaisquer outros elementos que possam prejudicar a aderência do produto, lavar com escova de aço e água. Reparar possíveis "nichos" e falhas de concretagem com argamassa de cimento e areia média lavada, traço 1:3. Umedecer a superfície antes da aplicação da primeira demão, tomando cuidado para não saturá-la. Aplicar argamassa polimérica com vassoura de pelos macios trincha pincel ou broxa, com consumo aproximado de $1,0 \mathrm{~kg}$ de massa fresca por metro quadrado de área $\left(1,0 \mathrm{~kg} / \mathrm{m}^{2}\right)$ por demão. Aplicar duas demãos cruzadas do produto. Aplicar argamassa polimérica, da mesma forma, com vassoura de pêlos macios, trincha, pincel ou broxa, com consumo aproximado de 1,0 kg de massa fresca por metro quadrado de área $\left(1,0 \mathrm{~kg} / \mathrm{m}^{2}\right)$ por demão. Entre a primeira e a segunda demão, fixar tela de poliéster para auxiliar na estruturação da membrana. Aplicar quatro demãos cruzadas do produto, ao todo. As demais demãos devem ser aplicadas após a anterior ter endurecido ou apresentado secagem ao toque ( 3 a 6 horas, dependendo das condições locais de temperatura e umidade).

Como não houve possibilidade de esvaziamento dos reservatórios não se pôde certificar se todos eles apresentavam armaduras expostas (enferrujadas) no seu interior, o que leva a sugerir que, quando da manutenção e limpeza semestral, deve-se verificar a integridade do concreto e das armaduras do interior dos reservatórios.

Risco: C (Grau Crítico).

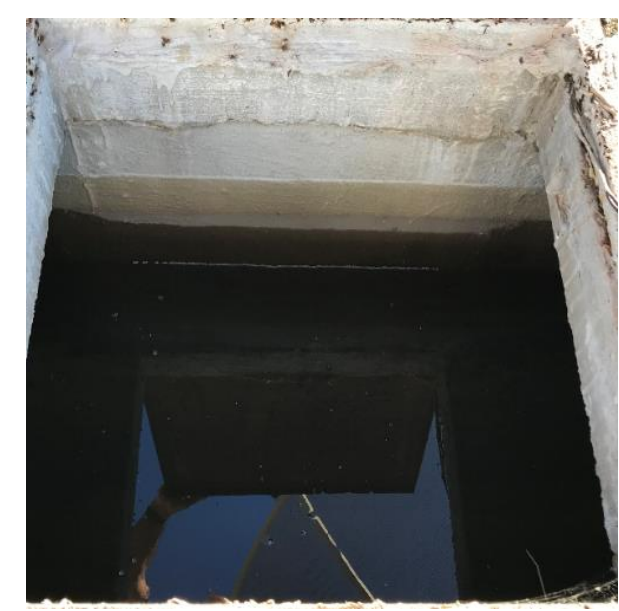

Figura 3 - Vista interna do reservatório de água superior

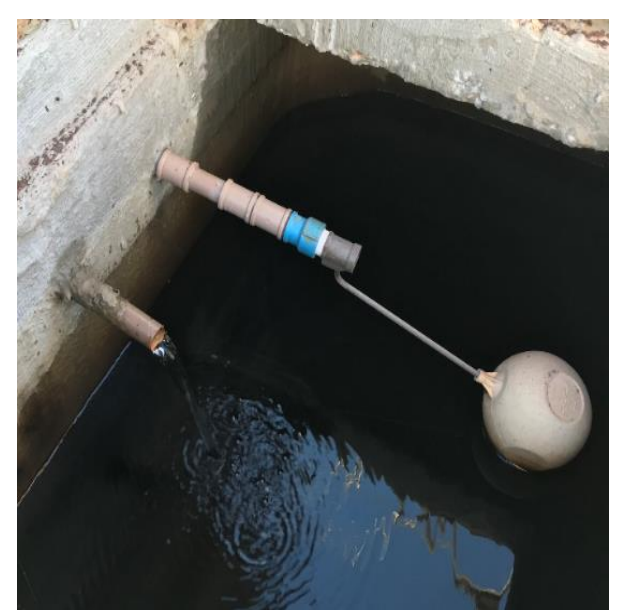

Figura 4 - Desgaste natural devido ao tempo de uso da impermeabilização interna do reservatório de água superior 


\subsection{Reservatórios superiores - impermeabilização da cobertura}

Manifestações: Na cobertura do reservatório foi identificada a falta de impermeabilização de toda a área do reservatório, o que pode ter provocando infiltrações de água da chuva na estrutura do reservatório. As Figuras 5 e 6 abaixo, apresentam a cobertura do reservatório sem qualquer revestimento de proteção. As infiltrações podem provocar uma cadeia de eventos que contribuem para a degradação das estruturas de concreto armado favorecendo a corrosão das armaduras e consequente destacamento do concreto que o recobre.

Classificação do Problema: falha na manutenção e anomalia construtiva

Possíveis Causas: falta de impermeabilização com manta de alumínio sobre os reservatórios que estão expostos a radiação solar e outras intempéries.

Este material, portanto, está sujeito a movimentos de expansão e retração constantes, com os ciclos climáticos diários, em que resfria e aquece. Observar a declividade adequada da laje para os pontos de drenagem (mínimo 1\%) e a capacidade dos drenos de esgotar a água acumulada, com diâmetros suficientes para este fim (mínimo $75 \mathrm{~mm}$ ).

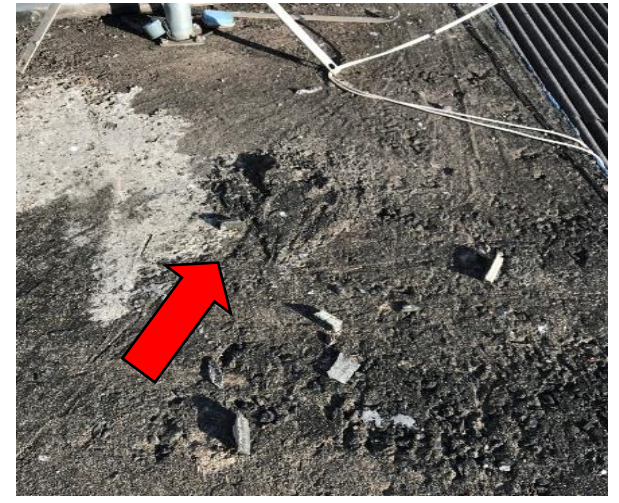

Figura 5 - Impermeabilização das lajes dos reservatórios

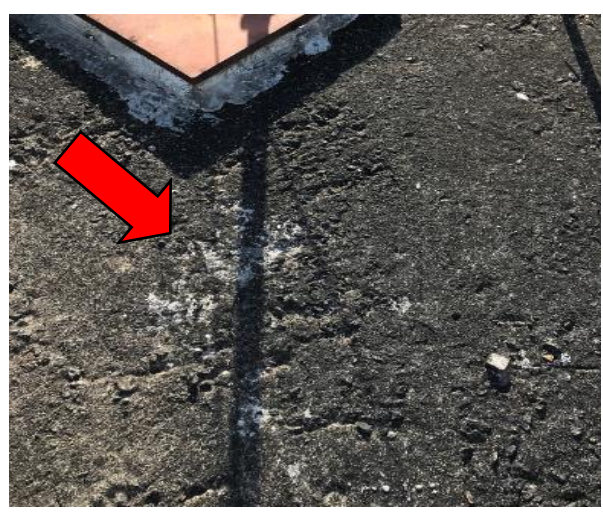

Figura 6 - Impermeabilização das lajes dos reservatórios

Intervenção: Para a impermeabilização da parte superior dos reservatórios, indica-se o uso da manta de alumínio (É uma manta estruturada com poliéster pré-estabilizado ou filme de polietileno de alta densidade auto protegida na face exposta com um filme de alumínio com alta resistência aos raios UV e grande flexibilidade. Apresenta refletância de até $93 \%$ dos raios solares e a capacidade de redução do ruído de impacto de chuva. Impermeabiliza e melhora o conforto térmico do ambiente).

Para a aplicação da manta de alumínio sugere-se o procedimento indicado pela ABNT NBR 9575 (2010) onde recomenda que seja feita a regularização das superfícies localizadas abaixo das mantas com argamassa desempenada de cimento e areia, com caimento mínimo de $1 \%$ em direção aos ralos ou drenos. Arredondar ou chanfrar cantos vivos e arestas, de forma a permitir um ajustamento contínuo do sistema impermeabilizante, sem dobragem em ângulo, tubulações emergentes e ralos que deverão estar rigidamente fixados, a fim de garantir a perfeita execução dos arremates. A execução de arremates no ralo ou dreno é, provavelmente, o detalhe mais importante do processo de impermeabilização. Tal execução é feita com aplicação de sucessivas demãos que adentram a abertura do piso, podendo ou não receber reforços de estruturantes têxteis e, quando aplicados à quente, devem ser dimensionados para suportar as temperaturas de aplicação. A já citada norma de impermeabilização, NBR 9575 (2010), refere que os coletores devem ter diâmetro que garanta a manutenção da seção nominal dos tubos prevista no projeto hidráulico após a execução da impermeabilização, sendo que o diâmetro nominal mínimo é $75 \mathrm{~mm}$.

Se houver na regiões barbacãs (drenos) na região em torno do ralo ou dreno deve ser executada um reforço de impermeabilização, sendo que esta deve ficar bem aderida à face interna do ralo. Caso contrário, a água será succionada por capilaridade para baixo da camada impermeabilizante.

Quando da aplicação da manta de alumínio, recomenda-se a limpeza do local, sem resíduos, restos de argamassa, madeiras, pontas de ferro, graxa, óleo e partículas soltas. Se necessário, lavar o local com 
hidrojateamento ou com escova de aço e água. Esperar secar. Para a aderência da manta em toda a área, incluindo rebaixos, aplicar uma demão de primer asfáltico. Aguardar a secagem do primer asfáltico, antes da colagem das mantas asfálticas aluminizadas. Com um maçarico de boca larga e gás GLP, aquecer o primer asfáltico e a parte inferior da manta asfáltica aluminizada até o plástico de proteção derreter. A chama do maçarico deve derreter superficialmente o filme de polietileno e o asfalto em toda a extensão da manta asfáltica aluminizada, deve-se evitar que a manta seja perfurada devido à intensidade e tempo prolongado de exposição à chama do maçarico. Sugere-se, nas paredes externas das casas de máquinas, caso as fissuras estejam realmente vedadas, a pintura com manta líquida com acabamento final com pintura. Todos os serviços acima descritos devem ser executados por profissionais legalmente habilitados e especializados, com Anotação de Responsabilidade Técnica (ART) registrada junto ao CREA-GO ou CAU-GO.

Risco: R (Grau Regular).

\subsection{Reservatórios superiores - manchas devidas a eflorescências (manchas brancas)}

Manifestações: Identificaram-se infiltrações, fissuras e manchas brancas (eflorescências) em elementos estruturais ao longo das paredes do reservatório superior, conforme figuras 7 e 8 .

Classificação do Problema: falha na manutenção e anomalia construtiva.

Possíveis causas: Devido ao tempo de uso do edifício, aproximadamente 20 anos, e a falta de manutenções periódicas, ocorrem fissuras internas e externas ao reservatório que se não recuperadas e protegidas com uma nova impermeabilização, podem gerar as eflorescências que trata-se de depósitos cristalinos de cor branca que surgem na superfície da estrutura e que resultam da exposição do concreto à água de infiltrações ou de intempéries.

A eflorescência pode induzir a degradação do concreto, quando a água infiltra nos poros do concreto, ela dissolve os sais presentes no cimento e na cal, principalmente o hidróxido de cálcio. Esses sais são conduzidos até a superfície durante a evaporação da água através da percolação (passagem da água pelo concreto). Com a evaporação da água, esses saís se cristalizam, gerando manchas de cor clara. Os depósitos podem aparecer pontualmente ou de forma generalizada, assim como podem se formar lenta ou rapidamente, dependendo do grau de exposição à umidade e à quantidade de sais presentes no concreto. Com a perda do hidróxido de cálcio ocorre a diminuição do $\mathrm{pH}$, tornando o ambiente interno ácido e fazendo com que as armaduras percam sua camada passivadora (proteção do aço) causando a oxidação da armadura.

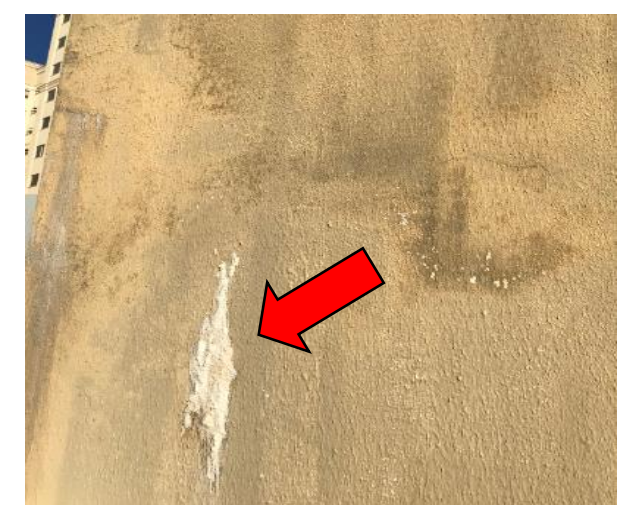

Figura 7 - Eflorescência

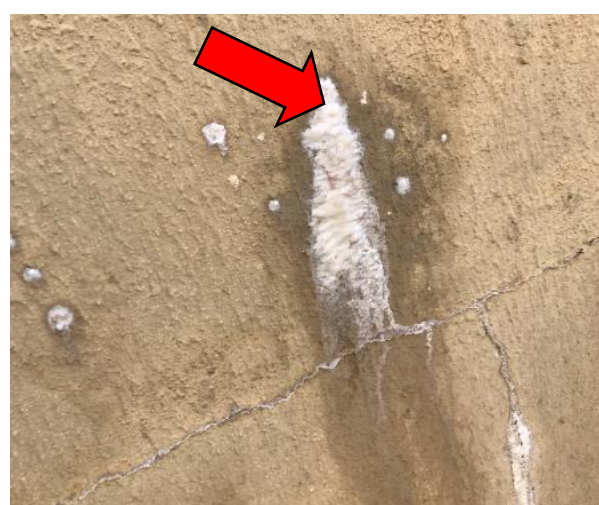

Figura 8 - Eflorescência

Intervenção: As eflorescências além de antiestéticas, são difíceis de serem removidas e podem comprometer a vida útil do reservatório e (ou) da estrutura. A deteç̧ão de eflorescência em estruturas de concreto exige intervenção rápida e assertiva. Como ocorre com outros tipos de manifestações patológicas, a primeira ação deve ser identificar e controlar a fonte do problema. Recuperar as fissuras e fazer uma nova impermeabilização do reservatório. As eflorescências salinas brancas podem ser removidas por escova a 
seco ou com água limpa e uma escova firme, ou em casos mais simples e superficiais, é possível remover os depósitos salinos com uma limpeza com ácido acético e água (proporção 1:1).

Risco: $\mathrm{R}$ (Grau regular).

\subsection{Pilotis - fissuras e destacamento do concreto na base de pilares}

Manifestações: Fissuras e destacamento do cobrimento do concreto na base dos pilares de concreto armado. $\mathrm{Na}$ figura 9 e 10 observa-se um avançado grau de destacamento do concreto.

Causa: Falha de manutenção e anomalia construtiva.

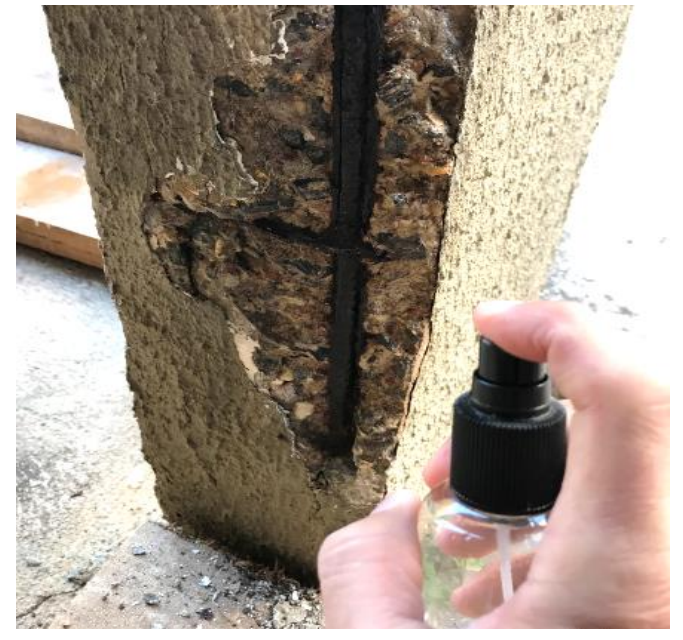

Figura 9- Aplicação de fenolftaleína

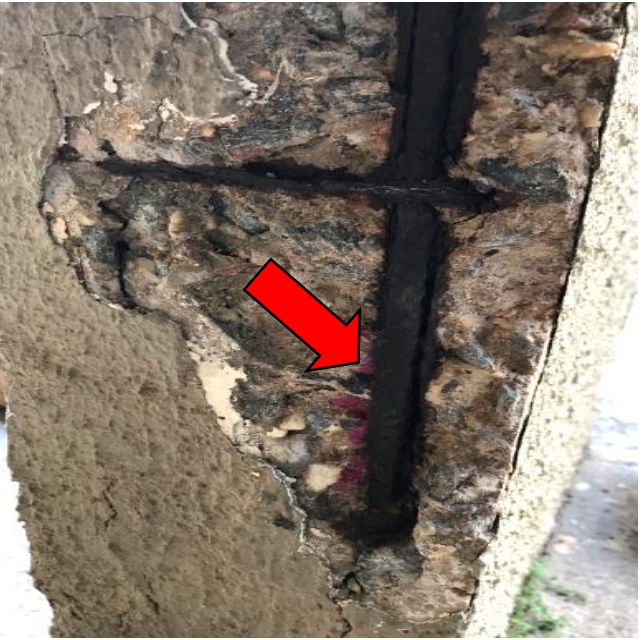

Figura 10 - Indicação do pH do concreto com carbonatação do pilar

Possíveis causas: Devido a exposição constante dos pilares do edifício ao sol, a chuva e ao dióxido de carbono $\left(\mathrm{CO}_{2}\right)$, expelido pelos automóveis, ocorre a carbonatação do concreto. A carbonatação se forma com umidade, gás carbônico e oxigênio. $\mathrm{O}$ mecanismo de deterioração do concreto ocorre quando a água $\left(\mathrm{H}_{2} \mathrm{O}\right)$, da chuva ou lavagem do piso, penetra pelas microfissuras do concreto, essa água $\left(\mathrm{H}_{2} \mathrm{O}\right)$ dissolve o cálcio $(\mathrm{Ca})$ presente na mistura do concreto formando o hidróxido de cálcio $\mathrm{Ca}(\mathrm{OH})_{2}$. O dióxido de carbono $\left(\mathrm{CO}_{2}\right)$ expelido pelos escapamentos dos veículos penetra também nessas fissuras e reage com a água formando o ácido carbônico $\left(\mathrm{H}_{2} \mathrm{CO}_{3}\right)$, esse gás carbônico reage com o hidróxido de cálcio formando cristais de Carbonato de Cálcio $\left(\mathrm{CaCO}_{3}\right)$, com essas reações ocorre a redução de Cálcio $(\mathrm{Ca})$ diminuindo o pH do concreto, deixando o aço da estrutura exposto à corrosão. Com a oxidação (ferrugem do aço) ocorre uma expansão e começam a ocorrer destacamentos do concreto, deixando a estrutura ainda mais exposta as intempéries e gerando novamente esse ciclo.

Intervenção: A frente de carbonatação do concreto é medida pelo emprego de indicador como a fenolftaleína que é borrifada na estrutura deteriorada (Figura 9), esse indicado é uma substância química que, em contato com a solução alcalina do concreto, rica em hidróxido de cálcio, adquire coloração vermelha carmim com pH igual ou superior a uma faixa entre 8,0 e 9,8, aproximadamente. Abaixo desses faixas de pH, o concreto tende a não sofrer alteração de cor quando da aspersão do indicador (mantém-se incolor). Temse, então, uma linha divisória entre a região incolor e a de coloração típica, uma clara evidência do avanço da frente de carbonatação para o interior do concreto de cobrimento. Em nível prático, portanto, admite-se que o concreto não está carbonatado quando, ao se aspergir o indicador, ele adquirir em sua superfície a coloração típica; caso fique incolor (Figura 10), assume-se que o concreto está carbonatado.

O concreto degrada-se naturalmente ao longo do tempo ou por causa de ações externas (como as explicadas acima) e falhas de execução. Como elemento estrutural de suma importância para a segurança, o concreto deve ser devidamente recuperado. 
Risco: C (Grau Crítico).

\section{Conclusão}

Dessa modo, os objetivos definidos para esse trabalho foram alcançados atraves da identificação das manifestações patológicas, por meio do registro fotográfico, e com a determinação das suas possíveis causas e soluções. Dentre as anomalis indicadas, tem-se destaque o reservatório superior, quanto ao desgaste da impermeabilização interna, pois esse tipo de manifestação pode resultar em infiltrações nos pavimentos inferiores, causando desconforto aos moradores, além de que com o tempo pode gerar uma condição favorável para a corrosão das armaduras da estruturas, como da laje de fundo do reservatório. Com isso, trata-se de uma intervenção com uma prioridade alta e requer atuação imediata.

Outra manifestação que exige atenção e também requer uma intervenção imediata, trata-se das fissuras e destacamentos do concreto nos pilotis. Esse tipo de anomalia exige uma prioridade alta em sua recuperação, pois ocorre em elementos que compõe a estrutura da edificação, a qual garante a estabilidade e estaticidade da construção, comprometendo assim a segurança dos usuários, além de afetar negativamente sobre o psicológico dos mesmos.

As demais manifestações apresentam grau regular e mínimo, variando de 1 até 3 anos para que seja feita intervenções. Dessa forma, nota-se que a maioria das manifestações patológicas identificadas apresentam como causa a falta de manutenção, demonstrando a extrema importância de que se realize manutenções preventivas para que consiga prolongar a vida útil da construção e também permita economia, visto que manutenções corretivas apresentam um custo superior.

Dessa forma, sugere-se que seja realizado manutenções e monitoramento periódicos de toda a edificação ao longo de sua vida útil. As sugestões de intervenções estruturais mencionadas nesta pesquisa são de caráter corretivo e preventivo, e buscam garantir a segurança dos condôminos e demais usuários. Além de servirem como referência para o desenvolvimento trabalhos futuros.

\section{Referências Bibliográficas}

ASSOCIAÇÃO BRASILEIRA DE NORMAS TÉCNICAS. NBR 16747 - Inspeção predial - Diretrizes, conceitos, terminologia e procedimento. Rio de Janeiro, 2020.

ASSOCIAÇÃO BRASILEIRA DE NORMAS TÉCNICAS. NBR 5674- Edificações - Procedimento. Rio de Janeiro, 1999.

BOLINA, F.; TUTIKIAN, B.; HELENE, P. Patologia de Estruturas. São Paulo: Oficina do Texto, 2019.

GALINDO, A. et al. Investigação das manifestaçõs patológicas de um edifício residencial localizado na cidade do Recipe-Pe. In: CONFERÊNCIA NACIONAL DE PATOLOGIA E RECUPERAÇÃO DE ESTRUTURAS, 2017, Recife. Anais..., Recife, 2017, 11p.

IBAPE. Norma de Inspeção Predial Nacional. São Paulo, 2012.

MORAIS, J. et al. Análise de manifestações patológicas em estruturas de concreto armado: uma revisão.Research, Society and Development, Itabira, v. 9, n. 7, p 1-32, 2020.

RIOS, E. et al. Carbonatação em estruturas de concreto armado: Diagnóstico do processo de carbonatação em lajes de concreto armado presentes no estacionamento de um edifício comercial na cidade de São Luís - MA. Brazilian Journal of Development, São José dos Pinhais, v. 6, n. 3, p. 15846-15869, 2020.

SOUZA, V.; RIPPER, T. Patologia, Recuperação e Reforço de Estruturas de Concreto. 1. ed. São Paulo: Editora Pini Ltda., 2009.

TUTIKIAN, B.; PACHECO, M. Boletim Técnico $n^{\circ} 1$ - Inspeção, Diagnóstico e Prognostico na Construção Civil. Mérida. 2013. 